\title{
The Lessons from Angelman Syndrome for Research and Management
}

\author{
Karine Pelc, Guy Cheron and Bernard Dan \\ Free University of Brussels \\ Belgium
}

\section{Introduction}

Interest in monogenic disorders with epilepsy has provided significant insights into the pathophysiology of epilepsy. Among these disorders, Angelman syndrome has attracted particular attention because of its complex genetics. Angelman syndrome is characterized by developmental delay, absence of speech, motor impairment, epilepsy and a peculiar behavioral phenotype with apparent happy demeanor. It is caused by the lack of expression of the $U B E 3 A$ gene, which can result from various abnormalities of chromosome 15q11-q13 if they concern the chromosome inherited from the mother (illustrating the phenomenon of genomic imprinting). In most case, Angelman syndrome is due to a de novo 15q11-q13 deletion. Rarely, patients have inherited both copies of chromosome 15 from the father and none from the mother, i.e. paternal uniparental disomy. As a result, no functional copy of the UBE3A gene is inherited from the mother. Patients with uniparental disomy have a statistically less severe phenotype than those with a deletion. Another small group of patients have an imprinting defect resulting in a lack of the typical maternal pattern of DNA methylation. Statistically, the phenotype of patients with an imprinting defect is indistinguishable form that of patients with uniparental disomy. In some patients, a mutation in the maternal $U B E 3 A$ gene can be detected, and in about $10 \%$ of typical cases, no cytogenetic or molecular abnormality can currently be found. Patients with Angelman syndrome have a remarkably high risk of epilepsy compared to many other neurodevelopmental disorders. In particular, early-childhood onset of refractory epilepsy with atypical absences and myoclonic seizures with predisposition to developing nonconvulsive status epilepticus is a common presentation. In recent years, there has been increasing awareness of epilepsy in adults. The neurocognitive effects of seizures are difficult to evaluate. Propensity to develop epilepsy may be due to hypersynchronous neuronal activity, which might be related to abnormal GABA-mediated transmission due to lack of UBE3A expression, or other factors. Recent findings in animal models demonstrated altered dendritic spine formation as well as both synaptic [GABA $A$ and NMDA transmission] and nonsynaptic (including gap junction) influences in various brain regions, including hippocampus and cerebellar cortex. Much research is still required to fully understand the functional links between lack of UBE3A expression and clinical manifestations of Angelman syndrome. Studies of regulation of UBE3A expression, including imprinting-related methylation, may point to possibilities of therapeutic 
upregulation. Understanding relevant roles of the gene product might lead to targeted intervention. Further documentation of brain network dynamics, with particular emphasis on hippocampus, thalamocortical, and cerebellar networks is needed, including in a developmental perspective. There is also a need for further clinical research for improving management of problems such as epilepsy, behavior, communication, learning, motor impairment, and sleep disturbances.

\section{Clinical features}

The clinical picture of Angelman syndrome has been broadly documented, principally in children, but with an increasing emphasis on adolescents and adults. Clinical diagnosis is based on a set of physical (Fig. 1) and behavioral features (Williams et al., 2006) (Table 1). All patients have developmental delay with severely impaired cognitive skills. They show specific speech impairment; about one-third of patients speak no words at all, and the others rarely use more than five words. This contrasts with better receptive verbal communication and communication skills based on spontaneous or learned signs. Behavior is characteristically overactive, exuberant, sociable, and happy, with frequent smiling and laughing (Pelc et al., 2008a). Developmental motor impairment includes mild to moderate axial hypotonia, present from birth, and eventual spastic hypertonia of the limbs that may become apparent during the first year of life (Dan \& Cheron, 2008). Despite varying degrees of ataxia, most patients develop independent walking. Gait is distinctive, with a wide support base, extension and lateral rotation of the lower limb, elbow flexion, and wrist supination. About $90 \%$ of patients have epileptic seizures. Seizure onset is often between 1 and 3 years. Many seizure types, both generalized and focal, have been reported, including epileptic spasms, myoclonic absences, myoclonic, atonic, tonic, and tonic-clonic seizures, but atypical absence and myoclonic seizures have been particularly emphasized. As in other developmental conditions with epilepsy, the seizure disorder often improves in late childhood, although epilepsy can persist or reappear in adulthood, and be difficult to

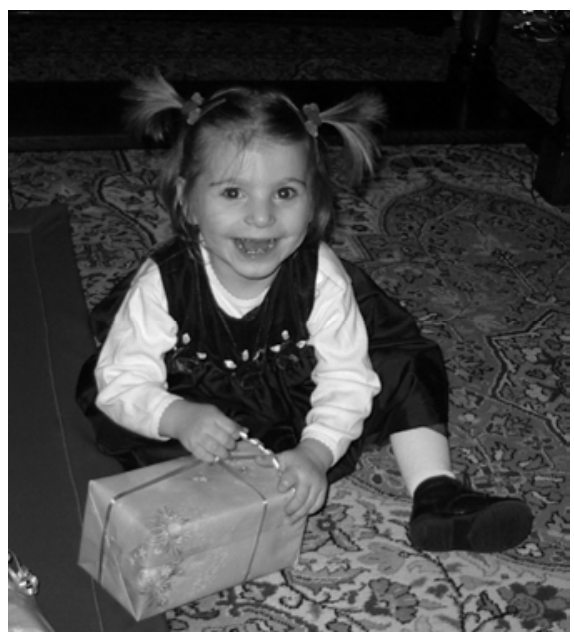

Fig. 1. Facial characteristics of a child with Angelman syndrome. Visual contact, fair eyes, midface hypoplasia, wide smiling mouth. 


\section{A. Consistent features (100\%)}

Developmental delay, functionally severe.

Movement or balance disorder, usually ataxia of gait, and/or tremulous movement of limbs. Movement disorder can be mild. May not appear as frank ataxia but can be forward lurching, unsteadiness, clumsiness, or quick, jerky motions

Behavioral uniqueness: any combination of frequent laughter/smiling; apparent happy demeanor; easily excitable personality, often with uplifted hand-flapping, or waving movements; hypermotor behavior

Speech impairment, none or minimal use of words; receptive and non-verbal communication skills higher than verbal ones

B. Frequent features (more than $80 \%$ )

Delayed, disproportionate growth in head circumference, usually resulting in microcephaly (-2 standard deviations of normal head circumference) by age 2 years. Microcephaly is more pronounced in those with 15q11.2-q13 deletions

Seizures, onset usually before 3 years of age. Seizure severity usually decreases with age but the seizure disorder lasts throughout adulthood

Abnormal electroencephalogram, with a characteristic pattern (Dan and Boyd 2003). The electroencephalographic abnormalities can occur in the first 2 years of life, can precede clinical features, and are often not correlated to clinical seizure events

C. Associated features $(20 \%-80 \%)$

Flat occiput

Occipital groove

Protruding tongue

Tongue thrusting; suck/swallowing disorders

Feeding problems and/or truncal hypotonia during infancy

Prognathia

Wide mouth, wide-spaced teeth

Frequent drooling

Excessive chewing/mouthing behaviors

Strabismus

Hypopigmented skin, light hair, and eye color compared to family, seen only in deletion cases

Hyperactive lower extremity deep tendon reflexes

Uplifted, flexed arm position especially during ambulation

Wide-based gait with pronated or valgus-positioned ankles

Increased sensitivity to heat

Abnormal sleep-wake cycles and diminished need for sleep

Attraction to/fascination with water; fascination with crinkly items such as certain papers and plastics

Abnormal food related behaviors

Obesity (in the older child)

Scoliosis

Constipation

Table 1. Clinical diagnostic criteria for Angelman syndrome. (Adapted from Williams et al 2006) 
control. Both convulsive and non-convulsive status epilepticus may occur. The latter isparticularly common during childhood, but it can occur in infancy and adulthood. In adolescents and adults, particularly, prolonged disabling tremor has been ascribed to cortical myoclonus (Guerrini et al., 1996) or myoclonic status (Ogawa et al., 1996; Elia, 2009). Piracetam, levetiracetam, topiramate and other antiepileptic drugs can be tried with variable results. The underlying mechanism remains unclear. It seems to be non-epileptic at least in some cases, where response to levodopa (Harbord, 2001) or reserpine (Stecker \& Myers, 2003) has been documented. Sleep problems commonly reduced total sleep time, increased sleep onset latency, disrupted sleep architecture with frequent nocturnal awakenings, reduced rapid eye movement (REM) sleep, and periodic leg movements.

\section{Natural history of the seizure disorder}

Onset of seizures is often before 3 years of age, mostly between 1 and 3 years (Buntinx et al., 1995; Buoni et al., 1999; Clayton-Smith, 1993; Saitoh et al., 1994). Whereas epilepsy is often a prominent clinical problem in childhood, seizure onset occurs during infancy in a minority of patients. If seizures do occur in infants, they tend to do so in a febrile context. In a high proportion of patients, the onset of epilepsy precedes the diagnosis of Angelman syndrome (Valente et al., 2006). Seizure types may evolve with age (Matsumoto et al., 1992; Uemura et al., 2005). As in other developmental conditions with epilepsy, the seizure disorder often improves in late childhood. Sustained seizure-freedom following epilepsy in childhood has been found in four of five patients with a 15q11-q13 deletion followed up longitudinally until the age of 30 years or more (Uemura et al., 2005). Other studies, however, have shown that epilepsy can persist or reappear in adulthood (Moncla et al., 1999; Thomson et al., 2006).

\section{Seizure types}

Many different types of seizures have been reported, both generalized and focal. They include myoclonic absences, myoclonic, atonic, tonic and tonic-clonic seizures (Cersósimo et al., 2003; Elia et al., 1998; Galván-Manso et al., 2002; Laan et al., 1997; Matsumoto et al., 1992; Minassian et al., 1998; Viani et al., 1995). Atypical absence and myoclonic seizures have been particularly emphasized. Multiple seizure types occur in about half of the patients with a 15q11-q13 deletion (Valente et al., 2006). Patterns of seizures, including type, age of onset, other clinical features and electroencephalographic features of patients with Angelman syndrome may show some resemblance with defined epileptic syndromes. In this context, it is important to characterise their epilepsy correctly given implications for both management and prognosis. Although epileptic spasms are the typical seizure type of West syndrome or infantile spasms (in association with hypsarrhythmic electrencephalogram and 'developmental arrest'), this epileptic syndrome has rarely been documented convincingly in Angelman syndrome. In the vast majority of cases, the electrencephalographic patterns seen in Angelman syndrome can be differentiated easily from hypsarrhythmia (Dan \& Boyd, 2003). The most commonly identified of these typical patterns consists of runs of rhythmic $2-3 / \mathrm{s}$ activity of high amplitude often exceeding $300 \mathrm{mV}$ seen mainly over the frontal regions (Boyd et al., 1988, 1997; Korff et al., 2005; Laan et al., 1997; Valente et al., 2003 ) i.e. Pattern I in Dan and Boyd's classification (Dan \& Boyd, 2003). Although tonic seizures and complex absences can occur in Angelman syndrome, confusion with Lennox-Gastaut syndrome can be avoided without much difficulty in many cases. Confusion with the 
electroencephalographic features of Lennox- Gastaut syndrome has also arisen in some reports, although the runs of slow spike-wave complexes seen in Angelman syndrome are usually rhythmic and signal non-convulsive status epilepticus (which has no specific features and is indeed indistinguishable from that seen in Lennox-Gastaut). In contrast, another epileptic syndrome, referred to as myoclonic status in non-progressive encephalopathies, has been appropriately recognised in a number of patients with Angelman syndrome (Dalla Bernardina et al., 1995). This syndrome is characterised by recurrent episodes of myoclonic status in patients who have pre-existing non-progressive neurological deficits including severe intellectual disability, axial hypotonia and ataxia (Dalla Bernardina et al., as cited in Roger et al., 1983) It also occurs in Wolff-Hirschhorn syndrome (4p-syndrome), neonatal encephalopathy and metabolic disorders such as nonketotic hyperglycinaemia. Another condition, which is not an epileptic syndrome stricto sensu in the absence of seizures, is electric status epilepticus during sleep, also known as continuous spike-wave discharges during sleep. The electroencephalographic features consists of generalised slow (usually around 2/s) spike-wave complexes, sometimes with a frontal emphasis, occupying more than $85 \%$ of slow-wave sleep, while this activity is exceedingly rare in rapid eye movement sleep. When the triad of electroencephalographic continuous spike-wave discharges during sleep, seizures (all types can occur except for tonic seizures) and impairment of neuropsychological and motor (e.g. ataxia) function is present, the condition can be regarded as an epileptic syndrome termed 'epilepsy with continuous spike-wave discharges during sleep'. This syndrome has rarely been documented in Angelman syndrome (Rubin et al., 1997). The lack of clinical alteration concomitant to the electrographic epileptiform activity excludes it from the context of nonconvulsive status epilepticus (Dan \& Boyd, 2005). Both convulsive and non-convulsive status epilepticus may occur. Compared to other conditions with epilepsy, the latter is relatively common, including in cases that are not due to 15q11-q13 deletion (Boyd et al., 1997; Laan et al., 1997; Uemura et al., 2005; Viani et al., 1995). Although non-convulsive status epilepticus appears to be more common during childhood, it can occur in infancy (Ogawa et al., 1996) and adulthood (Espay et al., 2005). Electroencephalogram shows continuous epileptic discharges which are distinct from the typical rhythmic electroencephalographic features of Angelman syndrome (Dan \& Boyd, 2003). The distinction between generalised and complex partial non-convulsive status epilepticus is often difficult to make. The term 'dialeptic status epilepticus', which refers to seizure phenomenology with alteration of consciousness as main ictal feature without any reference to the origin, might appear more appropriate in this context (Dan \& Boyd 2005). Frequent or prolonged episodes of dialeptic status epilepticus may contribute to a poor cognitive outcome, as suggested in other conditions with epilepsy (Hoffmann-Riem et al., 2000). In some cases, prolonged disabling tremor has been ascribed to cortical myoclonus (Guerrini et al., 1996) or myoclonic status (Ogawa et al., 1996). Such disabling resting tremor may appear in day-long clusters, particularly in adolescents or adults (Clayton-Smith, 2001; Van Buggenhout et al., 2000). When severe, it may result in loss of ability to eat or walk independently during episodes. The aetiology of this tremor remains unclear. It seems to be non-epileptic in a number of cases. In one report of two adult patients, associated cogwheeltype rigidity and bradykinesia suggested Parkinsonism and tremor improved dramatically on levodopa (Harbord, 2001). In another young adult, episodes of generalised shaking predominating in the upper extremities were correlated with 4-10/s electromyographic bursts but no ictal electroencephalographic changes (Stecker \& Myers, 2003). The 
electromyographic features were similar to the postural bursting activity described in children with Angelman syndrome (Dan \& Cheron, 2004) although the latter was not associated with actual tremor. The muscle activity associated with the movements was so intense that it induced hyperthermia and rhabdomyolysis. The movements were effectively controlled by reserpine in association with topiramate. This prominent, quasi-clonic activity may be difficult to distinguish from myoclonus. In a few other cases, fast-bursting myoclonus has been correlated with electroencephalographic activity of similar frequency or at subharmonics, suggesting cortical myoclonus (Guerrini et al., 1996; Ogawa et al., 1996 ) similar to findings in Rett syndrome (Guerrini et al., 1998). Finally, it must be noted that absence of electroencephalographic discharges correlated with bouts of laughter suggests that they do not correspond to gelastic seizures. Other possibly challenging spells include stereotyped movements, tremors, staring episodes, eye rolling, motor/behavioural manifestations of gastro-oesophageal reflux (Sandifer syndrome) and self-gratification episodes ('masturbation').

\section{Management}

Seizures may be difficult to control with pharmacological treatment, particularly in childhood. Surveys of antiepileptic drugs used in patients with Angelman syndrome have suggested that sodium valproate is the most commonly used (Ruggieri \& McShane, 1998). The use of clonazepam has also been reported in a number of cases. These drugs have been recommended on the basis of early reports of retrospective, open studies of limited patient series. The effectiveness of other benzodiazepines, such as nitrazepam and clobazam, seems to be similar to that of clonazepam in patients with Angelman syndrome (Østergaard \& Balslev, 2001). However, in the majority of patients, the use of benzodiazepines does not appear to be justified as a first-line treatment. Phenobarbitone can be both effective and well tolerated in infants. Because of sedative or cognitive side effects, it is less used in children and older patients. However, Clayton-Smith and Laan have suggested that it may be a good option in adults (Clayton-Smith \& Laan, 2003). Levetiracetam, topiramate, ethosuximide and lamotrigine have been successfully used in many cases, but there is a lack of controlled studies. It is noteworthy that although lamotrigine drug has no direct effect on GABAA receptors (Gibbs et al., 2002) it might promote GABRB3 gene expression in hippocampal cells (Dan et al, 2007). Some antiepileptic drugs may be paradoxically detrimental through increase in the risk of seizures, facilitation of the development of other seizure types or precipitation of non-convulsive status epilepticus. These drugs include carbamazepine (Minassian et al., 1998; Valente et al., 2006; Laan et al., 1996) oxcarbazepine (Valente et al., 2006) vigabatrin (Kuenzle et al., 1998; Østergaard \& Balslev, 2001; Valente et al., 2006) tiagabine and probably gabapentin. However, this observation does not imply absolute contraindication of these drugs, which may prove useful in some patients. This aggravation due to antiepileptic drugs is not specific to Angelman syndrome, where it appears to be more marginal than in some epileptic syndrome, notably idiopathic generalised epilepsies. Response of non-convulsive status epilepticus to treatment is variable and management may be difficult. Oral benzodiazepines, corticosteroids and ketamine (Mewasingh et al., 2003) may be early options, but there has been a marked lack of well-designed studies. Morbidity associated with aggressive treatment mayoutweigh the risk of therapeutic abstention. In contrast, convulsive status epilepticus requires early effective treatment according to common treatment protocols. Non-pharmacological management is rarely 
considered, despite the relatively high prevalence of drug resistance. Ketogenic diet was effective in four patients with refractory epilepsy in Valente et al.'s series (Valente et al., 2006).

\section{Neurophysiologic features}

The contribution of EEG to diagnosis of Angelman syndrome has been recognized in both children (Boyd et al., 1988; Korff et al., 2005; Rubin et al., 1997) and adults (Sandanam et al., 1997; Van Buggenhout et al., 2000), and particularly highlighted in infants (Van Lierde et al., 1990). In contrast to the paucity of physiologic rhythms, interictal EEG shows three distinctive high-amplitude rhythmic patterns (Dan \& Boyd, 2003), which can reinforce the clinical diagnosis (Williams et al., 2006). The most commonly identified EEG abnormality (pattern I) consists of runs of high amplitude rhythmic 2-3 Hz (delta) activity, seen mainly over the frontal regions (Fig. 2A). A variant composed of sharp slow waves (Fig. 2B) has been characterized as "triphasic" (Laan et al., 1997), "triphasic-like" (Valente et al., 2003), "polyphasic slow waves" (Minassian et al., 1998), "pattern IB" (Dan \& Boyd, 2003), or "notched delta" (Korff et al., 2005). Another pattern consisting of prolonged runs of rhythmic 4-6 Hz (theta) activity with centrotemporal emphasis (pattern II, Fig. 2C) is common in young children (Rubin et al., 1997), but tends to disappear after 5 (Boyd et al.,
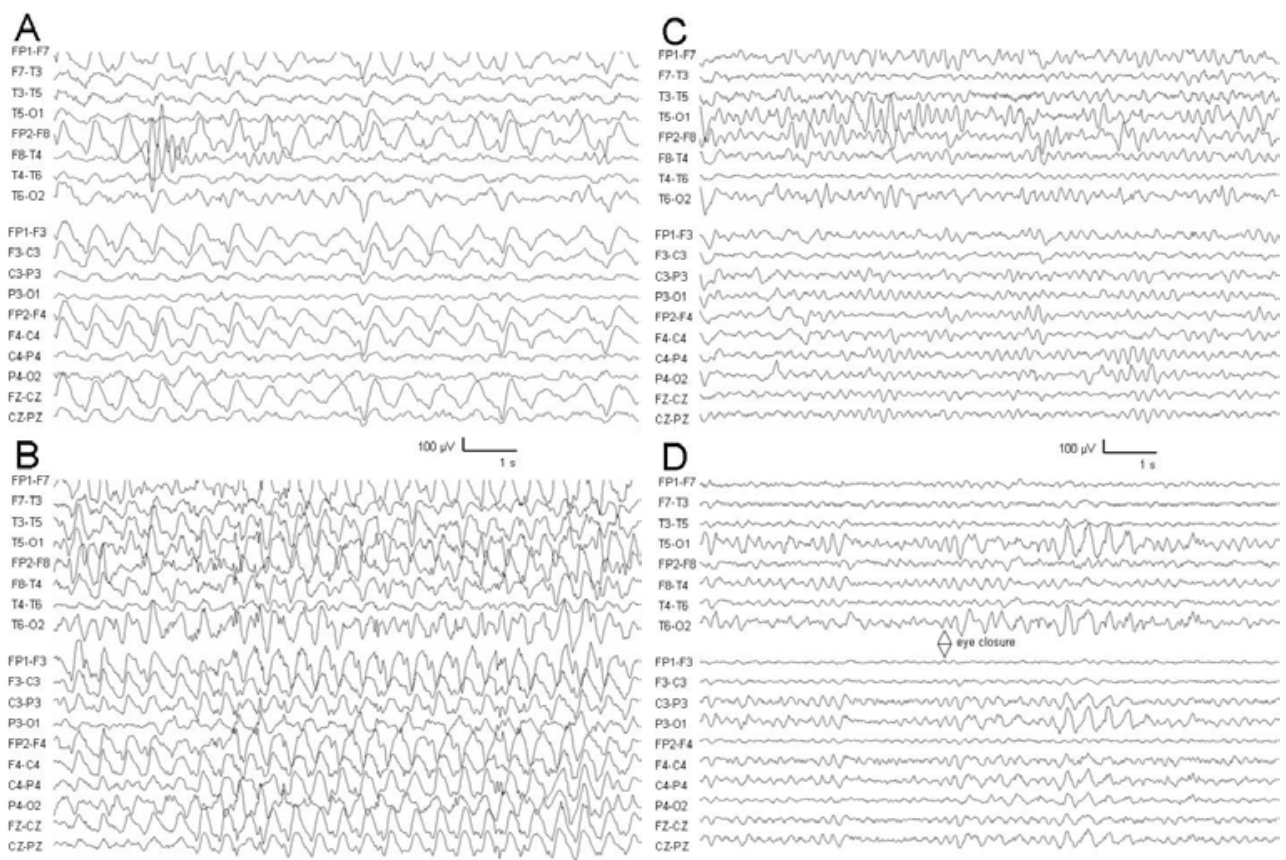

Fig. 2. Typical rhythmic electroencephalographic patterns. A, B. Pattern I: run of highamplitude delta activity mixedwith spikes predominating in the anterior regions without clinical correlation. C. Pattern II: run of diffuse moderate-amplitude theta activity. D. Pattern III: high amplitude delta activity mixed with spikes in the posterior regions on eye closure. 
1988) to 12 (Laan et al., 1997) years of age. Pattern III consists of high amplitude 3-6/s rhythmic activity sometimes containing small spikes, predominating over posterior regions (Fig. 2D). Eye closure facilitates its occurrence (Boyd et al., 1988; Rubin et al., 1997; Viani et al., 1995). In addition to these characteristic rhythmic activities, electroencephalography (EEG) may show epileptic discharges. Interictal nonspecific discharges including spikes, spike-waves, polyspike-wave, and more rarely bursts of fast sharp activity (Cersósimo et al., 2003) may show focal or generalized distribution. A few patients show prolonged runs of 2 $3 \mathrm{~Hz}$ spike-wave complexes without any clinical correlation (Dan et al., 2000; Matsumoto et al., 1992; Uemura et al., 2005).

\section{Genetic aspects}

In more than $90 \%$ of patients with a clinical diagnosis of Angelman syndrome, genetic testing can demonstrate a molecular mechanism causing lack of expression of the UBE3A gene. This gene is imprinted in (at least) some brain cells (Rougeulle et al., 1997), being expressed only from the chromosome 15 that is inherited from the mother. In about $70 \%$ of patients with Angelman syndrome, lack of UBE3A expression is due to microdeletion of the 15q11-q13 region on the maternally inherited chromosome 15. Similar abnormalities affecting the paternally inherited chromosome 15 result in Prader-Willi syndrome, a clinically distinct condition (Knoll et al., 1989). This illustrates genomic imprinting, where expression of imprinted genes is effectively monoallelic and depends on the paternal or maternal origin. This nonmendelian type of inheritance in human disease also prevails in Huntington disease, Beckwith-Wiedemann syndrome, and Silver- Russell syndrome. Other genes are implicated in the deletion, possibly resulting in a contiguous gene syndrome. The ATP10C gene is expressed preferentially from the maternal chromosome only; lack of its expression may underlie eventual obesity (Meguro et al., 2001). "Pinkeyed dilution" or P gene has been implicated in hypopigmentation that is seen in patients with a 15q11-13 microdeletion, characterized by light skin, reduced retinal pigment, low hair bulb tyrosinase activity, and incomplete melanosome melanization (King et al., 1993). Absence of a copy of the GABRB3, GABRG3, and GABRA5 genes, which code for subunits of GABAA receptor, has tentatively been related to abnormalities in GABAergic neurotransmission (Olsen \& Avoli, 1997). There is a mutation in the maternal UBE3A gene (Kishino et al., 1997; Matsuura et al., 1997) in another 5-10\% of patients (Lossie et al., 2001; Malzac et al., 1998). About 3-5\% of patients have an imprinting defect resulting in lack of the typical maternal pattern of DNA methylation required for UBE3A expression (Buiting et al., 1995). Approximately 2$3 \%$ of patients inherited both copies of chromosome 15 from the father and none from the mother, that is, paternal uniparental disomy (Malcolm et al., 1991); as a result, no functional copy of the UBE3A gene is inherited from the mother. Finally, $1-2 \%$ of patients have complex structural chromosome abnormalities leading to inactivation of the maternal UBE3A gene (Chan et al., 1993). To some extent, these molecular categories can be linked to two phenotypic pictures. One is more severe and seen in association with 15q11-q13 microdeletion or UBE3A mutation, that is, with only one intact copy of the UBE3A gene, which does not bear a maternal methylation pattern. Patients in those groups tend to have more severe microcephaly, greater delay in developmental milestones, more severely impaired communication skills, more severe seizures, and show hypopigmentation (Bürger et al., 1996; Lossie et al., 2001; Minassian et al., 1998; Moncla et al., 1999). The other phenotypic picture is relatively less severe, with low incidence of microcephaly, of hypopigmentation, less severe seizures, and more words, although speech is extremely 
limited and not used as a main communication tool. It is seen in association with uniparental disomy or imprinting defect, that is, with two intact copies of the UBE3A gene, none of which bear a maternal methylation pattern. However, the core phenotypic features, including the rhythmic EEG patterns described earlier, are shared, and there is much overlap in their severity across patients in all molecular classes. Genetic testing, therefore, has confirmatory rather than prognostic value. Nevertheless, obtaining a precise genetic diagnosis is essential in view of the complexity of genetic counseling.

\section{Animal models}

Molecular characterization of Angelman syndrome has allowed the development of animal models of the different mechanisms underlying the syndrome. Such models provide important insights into the pathophysiologic mechanisms involved in various aspects of Angelman syndrome. A mouse model of maternal microdeletion including the Ube3a gene did not result in obvious phenotypic abnormalities, but fine phenotypic aspects, such as motor control, learning skills, or neurophysiological features, have not been studied (Gabriel et al., 1999). This model is potentially very interesting, as it would represent the most prevalent situation in the human condition. The absence of a drastic phenotype, however, contrasts with Angelman syndrome. A model of Angelman syndrome due to paternal uniparental disomy showed high incidence of failure to thrive for the first 4-5 weeks and spontaneous death in the first month (Cattanach et al., 1997). Survivors developed obesity, hyperactive behavior, and gait described as "ataxic." Electrocorticographic recordings showed bilateral prolonged runs of high-amplitude delta rhythmic activity. The phenotype of proposed models of imprinting defect (Wu et al., 2006) has not been studied in detail, but mice showed a marked decrease in Ube3a (the gene product) in both the cerebral cortex and cerebellum. Mice with selective maternal Ube3a gene inactivation, providing models of Angelman syndrome due to maternally-inherited UBE3A gene mutation, showed no obvious phenotypic abnormality, but fine testing revealed impaired motor coordination and learning (Jiang et al., 1998; Miura et al., 2002). One of these models showed contextdependent learning impairment and deficits in hippocampal long-term potentiation (Weeber et al., 2003). These abnormalities have been related to diminished calcium/ calmodulin-dependent protein kinase II activity, which was secondary to altered autophosphorylation. More recently, van Woerden et al. demonstrated that loss of this selfinhibition resulted in improvement of both learning defects and synaptic plasticity (van Woerden et al., 2007). This mouse model also showed abnormal dendritic spine development in hippocampal

pyramidal neurons (Dindot et al., 2008). Electrocorticographic recordings showed almost continuous runs of rhythmic 3/s activity mixed with polyspikes and slow waves (Jiang et al., 1998). In another mouse model with targeted inactivation of maternal Ube3a (Miura et al., 2002), hippocampal electrocorticographic recordings showed runs of high amplitude 4-5/s spike-waves. Intracerebellar recordings in alert mice showed local field potential high frequency (ca. $160 \mathrm{~Hz}$ ) oscillation correlating with increased Purkinje cell firing rate and rhythmicity (Cheron et al., 2005, 2008).This oscillation was inhibited by gap junction, NMDA, or GABAA receptor blockers. In sleep, these mice showed reduced proportions of slowwave sleep (Colas et al., 2005). Among mouse models that do not involve Ube3a expression, the most relevant seems to be provided by mice that are deficient in the Gabrb3 gene (Homanics et al., 1997). Surviving homozygous knockout mice had seizures, hyperactive behavior, coordination and learning impairment (DeLorey et al., 1998; 
Homanics et al., 1997), reduced benzodiazepine binding to GABAA receptors in the cortex (Sinkkonen et al., 2003), and developmental changes in electrocorticographic recordings consisting of progressive slowing and subsequent appearance of highamplitude irregular slow and sharp waves, and generalized clonic seizures associated with spiking (DeLorey et al., 1998). In vitro electrophysiologic study suggested loss of reciprocal GABAergic inhibition between thalamic reticular neurons (Huntsman et al., 1999). Heterozygotes tended to show behaviors intermediate between wild-type and homozygous null mutants, with significant abnormalities in electrocorticography, seizures, and rest-activity patterns (DeLorey et al., 1998). This model shows interesting similarities with several phenotypic aspects of Angelman syndrome, mostly epilepsy. It has been particularly well studied from the neurophysiologic point of view. Recently, genetically engineered Drosophila with null Dube3a (UBE3A homolog) has been suggested as a model for Angelman syndrome (Wu et al., 2008). Mutants showed abnormal climbing behavior, impaired olfactory associative memory, and altered free-running circadian activity, which the authors tentatively related (in a somewhat far-fetched leap) with abnormal motor coordination, cognitive impairment, and sleep problems in patients with Angelman syndrome. Dube3a-null mutant flies also showed reduced dendritic branching of sensory neurons in the peripheral nervous system and altered growth of terminal dendritic processes (Lu et al., 2009).

\section{Pathophysiology}

Although the causative gene was identified more than 12 years ago (Kishino et al., 1997; Matsuura et al., 1997), underlying pathophysiology is still a matter of speculation. The gene product, UBE3A, acts as an E3 ubiquitin-protein ligase along the ubiquitin pathway. The best-characterized function of ubiquitination is to mark target proteins for specific proteolysis by proteasomes. Cytoplasmic accumulation of the p53 oncoprotein was found in Purkinje cells and in a subset of hippocampal neurons maternal Ube3a-deficient mice (Jiang et al., 1998). Because this protein is specifically ubiquitinated by UBE3A, the authors suggested that failure of Ube3a to ubiquitinate target proteins and promote their degradation could be a key aspect of the pathogenesis of Angelman syndrome. However, these findings have not been replicated in other models. Ubiquitin-mediated proteolysis may be important in a number of neuronal processes, including synaptogenesis and mechanisms of long-term memory. The ubiquitin pathway may also be involved in regulating abundance of postsynaptic receptors (Burbea et al., 2002). Functional absence of UBE3A might thus impair the regulation of GABAA receptors (Dan \&Boyd, 2003). In this hypothesis, altered regulation of b3 subunit-containing GABAA receptors would lead to "compensation" involving isoforms of the GABAA receptor that do not contain the b3 subunit, possibly changing the receptors' kinetics and desensitization properties. Although these changes are expected to be subtle, they may have extensive-but yet undocumentedeffects during brain maturation as well as through the patient's life. In patients with the common 15q11-q13 microdeletion, hemizygosity of GABAA receptor subunits a5, b3, and c3 has been suggested to underlie deficits in GABA-related neural synchrony mechanisms (Egawa et al., 2008). This could explain the propensity for more severe neurologic impairment in patients with 15q11-q13 microdeletion. Based on data from human patients and animal models, a model of thalamocortical dysfunction resulting from dysregulation of synaptic GABAergic neurotransmission has been proposed to account for the typical rhythmic EEG features (Dan \& Boyd, 2003). In this model, excessive neuronal synchrony precludes the generation complex spontaneous activity in neuronal networks and interferes 
with neuronal responsiveness. Synchronous network activity disrupts processing of inputs and, therefore, representation of information. Emergence of cerebellar oscillation in maternal Ube3a-deficient mice (Cheron et al., 2005) is consistent with a network mechanism implicating gap junctions and GABAA transmission (Dan et al., 2004; Traub et al., 2008). This oscillation shows similarities with various mouse models with altered calcium signaling (Cheron et al., 2008) and also involves NMDA transmission (Cheron et al., 2005). Hippocampal NMDA-dependent long-term potentiation abnormalities have also been documented in another model with inactivated maternal Ube3a (Weeber et al., 2003). In sum, formation of dendritic spines as well as both synaptic (including GABAA and NMDA transmission) and nonsynaptic (including gap junction) influences appear to be specifically altered in various brain regions (including hippocampus and cerebellar cortex). But much research is still required to fully understand the functional links between lack of UBE3A expression and the clinical manifestations of Angelman syndrome.

\section{Perspectives}

Despite the gaps that still preclude comprehensive understanding of Angelman syndrome, this condition potentially offers a powerful paradigm for both clinical and basic investigation of the complexity of brain maturation and motor, cognitive, and behavioral development (Scheiffele \& Beg, 2010). Most studies conducted until now have been retrospective and based on questionnaires. Such studies have mostly focused on issues relating to epilepsy, sleep, behavior, communication, or general health. Although large surveys are not expected to provide insights into mechanisms that lead to these manifestations, more studies are still required in these areas in order to add to the current body of knowledge and to refine the notions that have emerged. Given the trend for differences in severity of various phenotypic features between groups of patients from the different molecular classes, it would appear critical to carefully record the underlying genetic cause when constructing cohorts of patients. This might lead to the delineation of a typology of Angelman syndrome with multidimensional classification that could accommodate both milder and more severe atypical phenotypes. Studies of more homogenous categories thus defined would provide much-needed information about the natural history of specific subgroups. They would also make intervention- outcome studies more pertinent. Another key issue that has been overlooked in many previous surveys is the relationship between phenotypic expression and development. It is essential to take the dynamic aspects of development into account. Furthermore, it will become increasingly relevant to gather information about aging in Angelman syndrome. Relevant contextual factors need to be recognized. Quality-of-life issues need to be addressed. This should also encompass the psychological burden on both patients and caregivers, as well as coping strategies. Clinical studies could be considerably enhanced if a carefully designed largescale database could be set up with open access available to professionals. In this context, cross-study evaluation of various features, and their prevalence and natural history could be performed reliably. This would also allow assessment of the effect of management approaches. In connection with the neurology of Angelman syndrome, epilepsy has been the most studied subject. Controlled studies of treatment are still very much needed. Other neurologic features would also deserve special attention. With respect to motor control, for example, dysfunctions of various components of the motor system, including the motor cortex, cerebellum, and basal ganglia, have been hypothesized (Beckung et al., 2004; Dan et al., 2001, 2004; Harbord, 2001), but more studies are required to test the hypotheses. It is also 
important to further investigate cognition. Neuropsychological studies of well-defined subgroups of patients are necessary to shed more light on cognitive processing and learning strategies. This might have implications on the design of appropriate pedagogic approaches. Studies that are more pragmatic are also required, such as those that have assessed training programs (Didden et al., 2001). Almost all electrophysiologic studies conducted to date were limited to EEG, a number of them entertaining confusion between epileptic and nonepileptic changes. Recent methods analyzing brain dynamics and how it modulates neural processing can probably yield invaluable information. The typical rhythmic EEG activities likely reflect dynamic states of neural circuits. Experimental paradigms could be designed to analyze how these network activities are modulated by parameters such as attention or sensory inputs. Evoked-potential techniques (Egawa et al., 2008), and, in particular, "event-related potentials" will likely provide important information on specific aspects of brain functioning. Studies of processing of verbal language will be of special interest. Neuroimaging should also provide more insights into Angelman syndrome (Dan et al., 2009). The recent development of new analysis paradigms of MRI is likely to have implications in the documentation of alternative brain maturation in Angelman syndrome. Functional imaging can address a number of highly relevant issues, also including speech processing. There is also a great need for neuropathologic studies, as only two autopsies have been published. A large number of current studies concern molecular biology, including investigation of the mechanisms of imprinting and the possible roles of UBE3A. These studies are extremely important for achieving a better understanding of the involved processes. Based on this understanding, appropriate modulation might be proposed in order to improve neurologic functioning in patients with Angelman syndrome. Molecular biology studies must take into account possible differences between studied species. Among the most pressing questions that are yet to be solved, it will be crucial to discover the functions of UBE3A that are relevant to Angelman syndrome. This might open the way toward possible (partial) compensation for the virtual absence of UBE3A where and when it is needed. However, confusion may arise in association with the use of terms such as "cure" to characterize reversal of selected abnormalities in rescue genetically engineered animal models (Elgersma, 2007). "Cure" implies recovery from an illness, which is deceptive in this context. Brain development heavily relies on orderly processes that start in the embryo, drawing developmental trajectories. Although the issue of neuronal development has been poorly addressed in Angelman syndrome, it is likely to be altered given documented impairment in neuronal functioning in patients and animal models. Diagnosis is always made relatively late in the brain developmental history: late infancy at best and later childhood in most cases. Current research does not aim at discovering a cure but rather at improving management in order to optimize development, ameliorate symptoms, and improve of quality of life of children and adults with Angelman syndrome. In this context, it is important to consider that the effects of lack of UBE3A gene expression may represent an emergent property of developmental interactions among a number of brain regions and functions at the network level rather than a singular, localized dysfunction in otherwise normally developing central nervous system. Given the phenotypic variability even within a molecular class, it may prove important to dedicate attention to individuals' genetic, environmental, and/or developmental context as potential modulating factors. Another central question concerns the regulation of UBE3A gene expression in the hope that it can be enhanced. The phenotypic differences between patients who have one virtually nonfunctional copy of the UBE3A gene (i.e., patients with 15q11-q13 microdeletion or UBE3A inactivating mutation) and those who have two virtually nonfunctional copies (in case of uniparental 
disomy or imprinting defect) suggest that there is residual expression when the gene is intact, even in the absence of a functional methylation pattern. Although a dietary supplementation study did not bring about any clear clinical changes (Bacino et al., 2003), more topical intervention might prove useful. Another important question relates to determinants of the deleterious effect of absence of other genes in the 15q11-q13 region. This might explain phenotypic modulation in cases that are caused by a deletion. It might also point to requirements for compensation of lack of gene function. As suggested earlier, the putative roles played by GABRB3 may prove to be directly relevant to the function of UBE3A. Some studies concentrate on the possible relationship between genes implicated in Angelman syndrome and other conditions, such as Rett syndrome, autism, or epileptic syndromes. In particular, there seems to be some crucial interactions in the regulation of MECP2 and UBE3A expression (Samaco et al., 2005). There have been recent advances in this domain, which remain controversial (Jordan \& Francke, 2006). If the interactions are confirmed, there are likely to be found at multiple levels, perhaps including downstream effects on the regulation of the number of neurons, neuronal and synaptic structure or neurotransmission. Therefore, these interactions would potentially induce fundamental alterations in network properties of the central nervous system. This may also have therapeutic implications.

\section{References}

Angelman, H. (1965). 'Puppet' children: a report on three cases. Dev Med Child Neurol, 7:681688.

Bacino, C.A.; Peters, S.U.; Goddard-Finegold, J.; Smith, O.; O’Brien, W.; Madduri, N.; Glaze, D.; Shinawi, L. \& Beaudet, AL. (2003). A randomized therapeutic trial in Angelman syndrome using betaine and folic acid. Am J Hum Genet, 73(suppl):334.

Beckung, E.; Steffenburg, S. \& Kyllerman, M. (2004). Motor impairments, neurological signs, and developmental level in individuals with Angelman syndrome. Dev Med Child Neurol, 46:239-243.

Boyd, S.G.; Harden, A. \& Patton MA. (1988). The EEG in early diagnosis of the Angelman (happy puppet) syndrome. Eur J Pediatr, 147:508-513.

Boyd, S.G.; Cross, J.H. \& Dan, B. (1997). EEG features in Angelman syndrome. Eur J Paediatr Neurol, 1:A1-2.

Buiting, K.; Saitoh, S.; Groß, S.; Schwartz, S.; Nicholls, R.D. \& Horsthemke, B. (1995). Inherited microdeletions in the Angelman and Prader-Willi syndromes define an imprinting centre on human chromosome 15. Nature Genet, 9:395-400.

Buoni, S.; Grosso, S. ;Pucci, L. \& Fois, A. (1999).Diagnosis of Angelman syndrome: clinical and EEG criteria. Brain Dev, 21:296-302.

Burbea, M.; Drier, L.; Dittman, J.S.; Grunwald, M.E. \& Kaplan, J.M. (2002).Ubiquitin and AP180 regulate the abundance of GLR-1 Glutamate receptors at postsynaptic elements in C. elegans. Neuron, 33:107-120.

Bürger, J.; Kunze, J.; Sperling, K. \& Reis A. (1996). Phenotypic differences in Angelman syndrome patients: imprinting mutations show less frequently microcephaly and hypopigmentation than deletions. Am J Med Genet, 66:221-226.

Cattanach, B.M.; Barr, J.A.; Beechey, C.V.; Martin, J.; Noebels, J. \& Jones, J. (1997). A candidate model for Angelman syndrome in the mouse. Mamm Genome, 8:472-478.

Cersósimo, R.; Caraballo, R.; Espeche, A.; Cassar, L.; Torrado, M.V.; Chertkoff, L.; Baialardo, E.; Arroyo, H. \& Fejerman N. (2003). Síndrome de Angelman: características electroclínicas en 35 pacientes. Rev Neurol (Madrid), 37:14-18. 
Chan, C.T.J.; Clayton-Smith, J.; Cheng, X.J.; Buxton, J.; Webb, T.; Pembrey, M.E. \& Malcolm, S. (1993). Molecular mechanisms in Angelman syndrome: a survey of 93 patients. $J$ Med Genet, 30:895-902.

Cheron, G.; Servais, L.; Wagstaff, J. \& Dan B. (2005). Fast cerebellar oscillation associated with ataxia in a mouse model of Angelman syndrome. Neuroscience 130:631-637.

Cheron, G.; Servais, L. \& Dan B. (2008). Cerebellar network plasticity: from genes to fast oscillation. Neuroscience, 153:1-19.

Clayton-Smith, J. (1993). Clinical research on Angelman syndrome in the United Kingdom: observations on 82 affected individuals. Am J Med Genet, 46:12-15.

Clayton-Smith, J. (2001). Angelman syndrome: evolution of the phenotype

in adolescents and adults. Dev Med Child Neurol, 43:476-80.

Clayton-Smith, J. \& Laan, L. (2003) Angelman syndrome: a review of the clinical and genetic aspects. J Med Genet, 40:87-95.

Colas, D.; Wagstaff, J.; Fort, P.; Salvert, D. \& Sarda N. (2005). Sleep disturbances in Ube3a maternal-deficient mice modeling Angelman syndrome. Neurobiol Dis, 20:471-478.

Dalla Bernardina, B.; Trevisan, E.; Colamaria, V. \& Magaudda, A. Epilepsie myoclonique dans les encéphalopathies non progressives, In: Les syndromes épileptiques de l'enfant et de l'adolescent, Roger J, Dravet C, Bureau M, Dreifuss FE, Wolf P, pp. 68-72, John Libbey Eurotext, 1983. Paris

Dalla Bernardina, B.; Fontana, E.; Zullini, E.; La Selva, L.; Franco, A.; Darra, F. \& et al. (1995) Angelman syndrome: electroclinical features of 10 personal cases. Gaslini, 27(Suppl. 1):75-78.

Dan, B.; Boyd, S.G.; Christiaens, F.; Courtens, W.; Van Maldergem , L. \& Kahn

A. (2000). Atypical features in Angelman syndrome due to imprinting defect or uniparental disomy of chromosome 15. Neuropediatrics, 31:109-110.

Dan, B.; Bouillot, E.; Bengoetxea, A.; Boyd, S.G. \& Cheron, G. (2001). Distinct multi-joint control strategies in spastic diplegia associated with prematurity or Angelman syndrome. Clin Neurophysiol, 112:1618- 1625.

Dan, B. \& Boyd, S.G. (2003). Angelman syndrome reviewed from a neurophysiological perspective. The UBE3A-GABRB3 hypothesis. Neuropediatrics, 34:169-176.

Dan, B. \& Cheron, G. (2004). Postural rhythmic muscle bursting activity in Angelman syndrome. Brain Dev, 26:389-93.

Dan, B.; Servais, L.; Boyd, S.G.; Wagstaff, J. \& Cheron, G. (2004). From electrophysiology to chromatin: a bottom-up approach to Angelman syndrome. Ann $N$ Y Acad Sci, 1030:599-611.

Dan, B. \& Boyd, S.G. (2005). Nonconvulsive (dialeptic) status epilepticus in children. Curr Pediatr Rev, 1:7-16.

Dan, B.; Boyd, S.G.; Pelc, K. \& Cheron G. (2007). Lamotrigine effect on GABA transmission in Angelman syndrome? Epilepsia, 48:1634.

Dan, B. (2008). Angelman syndrome. Mac Keith Press, Wiley-Blackwell, ISBN: 1898683557, London.

Dan, B. \& Cheron, G. (2008). Postural control in children with Angelman syndrome or Rett syndrome. In (Eds) Posture: a key issue in developmental disorders, Hadders-Algra M, Brogren Carlberg E, pp. 148-169, Mac Keith Press, Wiley-Blackwell, ISBN 0-87993423-9, London.

Dan, B.; Pelc, K. \& Christophe, C. (2009). What would the brain look like in Angelman syndrome? Eur J Paediatr Neurol, 13:269-270.

DeLorey, T.M.; Handforth, A.; Anagnostaras, S.G.; Homanics, G.E.; Minassian, 
B.A.; Asatourian, A.; Fanselow, M.S.; Delgado-Escueta, A.; Ellison, G.D. \& Olsen, R.W. (1998). Mice lacking the beta3 subunit of the GABAA receptor have the epilepsy phenotype and many of the behavioral characteristics of Angelman syndrome. $J$ Neurosci, 18:8505-8514.

Didden, R.; Sikkema, S.P.E.; Bosman, I.T.M. \& Ducker, P.C. (2001). Use of a modified AzrinFoxx toilet training procedure with individuals with Angelman syndrome. J Appl Res Intellect Dis, 14:64-70.

Didden, R.; Korzilius, H.; Smits, M.G. \& Curfs, L.M.G. (2004). Sleep problems in individuals with Angelman syndrome. Am J Ment Retard, 109:275- 284.

Dindot, S.V.; Antalffy, B.A.; Bhattacharjee, M.B. \& Beaudet, A.L. (2008). The Angelman syndrome ubiquitin ligase localizes to the synapse and nucleus, and maternal deficiency results in abnormal dendritic spine morphology. Hum Mol Genet, 17:111118.

Egawa, K.; Asahina, N.; Shiraishi, H.; Kamada, K.; Takeuchi, F.; Nakane, S.; Sudo, A.; Kohsaka, S. \& Saitoh S. (2008). Aberrant somatosensoryevoked responses imply GABAergic dysfunction in Angelman syndrome. Neuroimage, 39:593-599.

Elgersma, Y. (2007). Genetic engineering cures mice of neurological deficits: prospects for treating Angelman syndrome. Pharmacogenomics, 8:539-541.

Elia, M.; Guerrini, R.; Musumeci, S.A.; Bonanni, P.; Gambardella, A. \& Aguglia, U. (1998). Myoclonic absence-like seizures and chromosome abnormality syndromes. Epilepsia, 39:660-663.

Elia, M. (2009). Myoclonic status in nonprogressive encephalopathies: an update. Epilepsia, 50 (suppl 5):41-44.

Espay, A.J.; Andrade, D.M. ; Wennberg, R.A. \& Lang, A.E. (2005). Atypical absences and recurrent absence status in an adult with Angelman syndrome due to the UBE3A mutation. Epileptic Disord, 7:227-230.

Gabriel, J.M.; Merchant, M.; Ohta, T.; Ji, Y.; Caldwell, R.G.; Ramsey, M.J.; Tucker, J.D.; Longnecker, R. \& Nicholls, R.D. (1999). A transgene insertion creating a heritable chromosome deletion mouse model of Prader-Willi and Angelman syndromes. Proc Natl Acad Sci USA, 96:9258-9263.

Galván-Manso, M.; Campistol, J.; Monros, E.; Póo, P.; Vernet, A.M.; Pineda, M. \& et al. (2002). Síndrome de Angelman: características físicas y fenotipo conductual en 37 pacientes con diagnóstico genético confirmado. Rev Neurol (Madrid), 35:425-9.

Gibbs III, J.W.; Zhang, Y.F.; Ahmed, H.S. \& Coulter, D.A. (2002). Anticonvulsant actions of lamotrigine on spontaneous thalamocortical rhythms. Epilepsia, 43:342-9.

Guerrini, R.; De Lorey, T.M.; Bonanni, P.; Moncla, A.; Dravet, C.; Suisse, G.; Livet, M.O.; Bureau, M.; Malzac, P.; Genton, P.; Thomas, P.; Sartucci, F.; Simi, P. \& Serratosa, J.M. (1996).Cortical myoclonus in Angelman syndrome. Ann Neurol, 40:39-48.

Guerrini, R.; Bonanni, P.; Parmeggiani, L.; Santucci, M.; Parmeggiani, A. \& Sartucci, F. (1998). Cortical reflex myoclonus in Rett syndrome. Ann Neurol, 43:472-9.

Harbord, M. (2001). Levodopa responsive Parkinsonism in adults with Angelman Syndrome. J Clin Neurosci, 8:421-422.

Hoffmann-Riem, M.; Diener, W.; Benninger, C.; Rating, D.; Unnebrink, K.; Stephani, U. \& et al. (2000). Nonconvulsive status epilepticus: a possible cause of mental retardation in patients with Lennox- Gastaut syndrome. Neuropediatrics, 31:169-74.

Homanics, G.E.; DeLorey, T.M.; Firestone, L.L.; Quinlan, J.J.; Handforth, A.; Harrison, N.L.; Krasowski, M.D.; Rick, C.E.; Korpi, E.R.; Mäkelä, R.; Brilliant, M.H.; Hagiwara, N.; Ferguson, C.; Snyder, K. \& Olsen, R.W. (1997). Mice devoid of gamma- 
aminobutyrate type A receptor beta3 subunit have epilepsy, cleft palate, and hypersensitive behavior. Proc Natl Acad Sci, 94:4143-4148.

Huntsman, M.M.; Porcello, D.M.; Homanics, G.E.; DeLorey, T.M. \& Huguenard, J. R. (1999). Reciprocal inhibitory connections and network synchrony in the mammalian thalamus. Science, 283:541-543.

Jiang, Y.H.; Armstrong, D.; Albrecht, U.; Atkins, C.M.; Noebels, J.L.; Eichele, G.; Sweatt, J.D. \& Beaudet, A.L. (1998).Mutation of the Angelman ubiquitin ligase in mice causes increased cytoplasmic p53 and deficits of contextual learning and long-term potentiation. Neuron, 21:799-811.

Jordan, C. \& Francke, U. (2006). Ube3a expression is not altered in Mecp2 mutant mice. Hum Mol Genet, 15:2210-2215.

King, R.A.; Wiesner, G.L.; Townsend, D. \& White, J.G. (1993). Hypopigmentation in Angelman syndrome. Am J Med Genet, 46:40-44.

Kishino, T.; Lalande, M. \& Wagstaff, J. (1997). UBE3A/E6-AP mutations cause Angelman syndrome. Nat Genet, 15:70-73.

Knoll, J.H.; Nicholls, R.D.; Magenis, R.E.; Graham, J.M. Jr.; Lalande, M. \& Latt, S.A. (1989). Angelman and Prader-Willi syndromes share a common chromosome 15 deletion but differ in parental origin of the deletion. Am J Med Genet, 32:285-290.

Korff, C.M.; Kelley, K.R. \& Nordli, D.R. (2005). Notched delta, phenotype, and Angelman syndrome. J Clin Neurophysiol, 22:238-243.

Kuenzle, C.; Steinlin, M.; Wohlrab, G.; Boltshauser, E. \& Schmitt, B. (1998). Adverse effects of vigabatrin in Angelman syndrome. Epilepsia, 39:1213 - 5.

Laan, L.A.E.M.; den Boer, A.T.H.; Hennekam, R.C.M.; Renier, W.O. \& Brouwer, O.F. (1996). Angelman syndrome in adulthood. Am J Med Genet, 66:356-60.

Laan L.A.E.M.; Renier, W.O.; Arts, W.F.M.; Buntinx, I.M.; vd Burgt, I.J.A.M.; Stroink, H.; Beuten, J.; Zwinderman, K.H.; van Dijk, J.G. \& Brouwer, O.F. (1997) Evolution of epilepsy and EEG findings in Angelman syndrome. Epilepsia, 38:195-199.

Lossie, A.C.; Whitney, M.M.; Amidon, D.; Dong, H.J.; Chen, P.; Theriaque, D.; Hutson, A.; Nicholls, R.D.; Zori, R.T.; Williams, C.A. \& Driscoll, D.J. (2001). Distinct phenotypes distinguish the molecular classes of Angelman syndrome. J Med Genet, 38:834-845.

Lu, Y.; Wang, F.; Li, Y.; Ferris, J.; Lee, J.A. \& Gao, F.B. (2009). The Drosophila homologue of the Angelman syndrome ubiquitin ligase regulates the formation of terminal dendritic branches. Hum Mol Genet, 18:454- 462.

Malcolm, S.; Clayton-Smith, J.; Nichols, M.; Robb, S.; Webb, T.; Armour, J.A.L.; Jeffreys, A.J. \& Pembrey, M.E. (1991). Uniparental paternal disomy in Angelman's syndrome. Lancet, 337:694-697.

Malzac, P.; Webber, H.; Moncla, A.; Graham, J.M. Jr.; Kukolich, M.; Williams, C.; Pagon, R.A.; Ramsdell, L.A.; Kishino, T. \& Wagstaff J. (1998). Mutation analysis in UBE3A in Angelman syndrome patients. Am J Hum Genet, 62:1353-1360.

Matsumoto, A.; Kumagai, T.; Miura, K.; Miyazaki, S.; Hayakawa, C. \& Yamanaka, T. (1992). Epilepsy in Angelman syndrome associated with chromosome 15q deletion. Epilepsia, 33:1083-1090.

Matsuura, T.; Sutcliffe, J.S.; Fang, P.; Galjaard, R.J.; Jiang, Y.H.; Benton, C.S.; Rommens, J.M. \& Beaudet, A.L. (1997). De novo truncating mutations in E6-AP ubiquitin-protein ligase gene (UBE3A) in Angelman syndrome. Nat Genet, 15:74-77.

Meguro, M.; Kashiwagi, A.; Mitsuya, K.; Nakao, M.; Kondo, I.; Saitoh, S. \& Oshimura, M. (2001). A novel maternally expressed gene, ATP10C, encodes a putative aminophospholipid translocase associated with Angelman syndrome. Nat Genet, 28:19-20. 
Mewasingh, L.D.; Sekhara, T.; Aeby, A.; Christiaens, F.J. \& Dan, B. (2003). Oral ketamine in paediatric non-convulsive status epilepticus. Seizure, 12:483-9.

Miano, S.; Bruni, O.; Elia, M.; Musumeci, S.A.; Verrillo, E. \& Ferri, R. (2005). Sleep breathing and periodic leg movement pattern in Angelman syndrome: a polysomnographic study. Clin Neurophysiol, 116:2685-2692.

Minassian, B.A.; DeLorey, T.M.; Olsen, R.W.; Philippart, M.; Bronstein, Y.; Zhang, Q.; Guerrini, R.; Van Ness, P.; Livet, M.O. \& Delgado-Escueta, A.V. (1998). Angelman syndrome: correlations between epilepsy phenotypes and genotypes. Ann Neurol, 43:485-493.

Miura, K.; Kishino, T.; Li, E.; Webber, H.; Dikkes, P.; Holmes, G.L. \& Wagstaff, J. (2002). Neurobehavioral and electroencephalographic abnormalities in Ube3a maternaldeficient mice. Neurobiol Dis, 9:149-159.

Moncla, A.; Malzac, P.; Voelckel, M.A.; Auquier, P.; Girardot, L.; Mattei, M.G.; Philip, N.; Mattei, J.F.; Lalande, M. \& Livet, M.O. (1999). Phenotype-genotype correlation in 20 deletion and 20 nondeletion Angelman syndrome patients. Eur J Hum Genet, 7:131-139.

Ogawa, K.; Ohtsuka, Y.; Kobayashi, K.; Asano, T. \& Oka, E. (1996). The characteristics of epilepsy with Angelman syndrome. Epilepsia, 37(suppl 3):83-84.

Olsen, R.W. \& Avoli, M. (1997). GABA and epileptogenesis. Epilepsia, 38:399-407.

Pelc, K.; Dachy, B.; Cheron, G. \& Dan, B. (2006). Postural cortical myoclonus in Rett syndrome. Rev Neurol (Madrid), 43:16.

Pelc, K.; Cheron, G. \& Dan, B. (2008a). Behavior and neuropsychiatric manifestations in Angelman syndrome. Neuropsychiatr Dis Treat, 4:577-584.

Pelc, K.; Boyd, S.G.; Cheron, G. \& Dan, B. (2008b). Epilepsy in Angelman syndrome. Seizure, 17:211-217.

Pelc, K.; Cheron, G.; Boyd, S.G. \& Dan, B. (2008c). Are there distinctive sleep problems in Angelman syndrome? Sleep Med, 9:434-441.

Petersen, M.B.; Brondum-Nielsen, K.; Hansen, L.K. \& Wulff; K. (1995). Clinical, cytogenetic, and molecular diagnosis of Angelman syndrome: estimated prevalence rate in a Danish county. Am J Med Genet, 60:261-262.

Rougeulle, C.; Glatt, H. \& Lalande, M. (1997). The Angelman syndrome candidate gene, UBE3A/E6-AP, is imprinted in brain. Nat Genet, 17:14-15.

Rubin, D.I.; Patterson, M.C.; Westmoreland, B.F. \& Klass, D.W. (1997). Angelman's syndrome: clinical and electroencephalographic findings. Electroencephalogr Clin Neurophysiol, 102:299-302.

Ruggieri, M. \& McShane, M.A. (1998). Parental view of epilepsy in Angelman syndrome: a questionnaire study. Arch Dis Child, 79:423-6.

Samaco, R.C.; Hogart, A.; Robson, L. \& LaSalle, J.M. (2005). Epigenetic overlap in autismspectrum neurodevelopmental disorders: MECP2 deficiency causes reduced expression of UBE3A and GABRB3. Hum Mol Genet, 14:483-492.

Sandanam, T.; Beange, H.; Robson, L.; Woolnough, H.; Buchholz, T. \& Smith, A. (1997). Manifestations in institutionalised adults with Angelman syndrome due to deletion. Am J Med Genet, 70:415-420.

Scheiffele, P. \& Beg, A.A. (2010). Angelman syndrome connections. Nature, 468: 907-908 Sinkkonen, S.T.; Homanics, G.E. \& Korpi, E.R. (2003). Mouse models of Angelman syndrome, a neurodevelopmental disorder, display different brain regional GABAA receptor alterations. Neurosci Lett, 340:205-208.

Stecker, M.M. \& Myers, S.M. (2003). Reserpine responsive myoclonus and hyperpyrexia in a patient with Angelman syndrome. Clin Neurol Neurosurg, 105:183-187. 
Thomson, A.K.; Glasson, E.J. \& Bittles, A.H. (2006). A long-term populationbased clinical and morbidity profile of Angelman syndrome in Western Australia: 1953-2003. Disabil Rehabil, 28:299-305.

Traub, R.D.; Middleton, S.J.; Knçpfel, T. \& Whittington, M.A. (2008). Model of very fast (> 75 $\mathrm{Hz}$ ) network oscillations generated by electrical coupling between the proximal axons of cerebellar Purkinje cells. Eur J Neurosci, 28:1603-1616.

Uemura, N.; Matsumoto, A.; Nakamura, M.; Watanabe, K.; Negoro, T.; Kumagai, T.; Miura, K.; Ohki, T.; Mizuno, S.; Okumura, A.; Aso, K.; Hayakawa, F. \& Kondo, Y. (2005). Evolution of seizures and electroencephalographical findings in 23 cases of deletion type Angelman syndrome. Brain Dev, 27:383-388.

Valente, K.D.; Andrade, J.Q.; Grossmann, R.M.; Kok, F.; Fridman, C.; Koiffmann, C.P. \& Marques-Dias, M.J. (2003). Angelman syndrome: difficulties in EEG pattern recognition and possible misinterpretations. Epilepsia, 44:1051-1063.

Valente, K.D.; Koiffmann, C.P.; Fridman, C.; Varella, M.; Kok, F.; Andrade, J.Q. \& et al. (2006). Epilepsy in patients with angelman syndrome caused by deletion of the chromosome 15q11-13. Arch Neurol, 63:122-8.

Van Buggenhout, G.J.; Descheemaeker, M.J.; Thiry, P.; Trommelen, J.C.; Hamel, B.C. \& Fryns, J.P. (2000). Angelman syndrome in three adult patients with atypical presentation and severe neurological complications. Genet Couns, 11:363-373.

Van Lierde, A.; Atza, M.G.; Giardino, D. \& Viani, F. (1990). Angelman's syndrome in the first year of life. Dev Med Child Neurol, 32:1011-1016.

Viani, F.; Romeo, A.; Viri, M.; Mastrangelo, M.; Lalatta, F.; Selicorni, A.; Gobbi, G.; Lanzi, G.; Bettio, D.; Briscioli, V.; Di Segni, M.; Parini, R. \& Terzoli, G. (1995). Seizure and EEG patterns in Angelman's syndrome. J Child Neurol, 10:467-471.

Walz, N.C.; Beebe, D. \& Byars, K. (2005). Sleep in individuals with Angelman syndrome: parent perceptions of patterns and problems. Am J Ment Retard, 110:243-252.

Weeber, E.J.; Jiang, Y.H.; Elgersma, Y.; Varga, A.W.; Carrasquillo, Y.; Brown, S.E.; Christian, J.M.; Mirnikjoo, B.; Silva, A.; Beaudet, A.L. \& Sweatt, J.D. (2003). Derangements of hippocampal calcium/calmodulin-dependent protein kinase II in a mouse model for Angelman mental retardation syndrome. J Neurosci, 23:2634-2644.

Williams, C.A.; Beaudet, A.L.; Clayton-Smith, J.; Knoll, J.H.; Kyllerman, M.; Laan, L.A.; Magenis, R.E.; Moncla, A.; Schinzel, A.A.; Summers, J.A. \& Wagstaff, J. (2006). Angelman syndrome 2005: updated consensus for diagnostic criteria. Am J Med Genet, 140:413-418.

van Woerden, G.M.; Harris, K.D.; Hojjati, M.R.; Gustin, R.M.; de Avila Freire, R.; Jiang, Y.H.; Elgersma, Y. \& Weeber, E.J. (2007). Rescue of neurological deficits in a mouse model for Angelman syndrome by reduction of CaMKII inhibitory phosphorylation. Nat Neurosci, 10:280-282.

Wu, M.Y.; Chen, K.S.; Bressler, J.; Hou, A.; Tsai, T.F. \& Beaudet, A.L. (2006). Mouse imprinting defect mutations that model Angelman syndrome. Genesis, 44:12-22.

Wu, Y.; Bolduc, F.V.; Bell, K.; Tully, T.; Fang, Y.; Sehgal, A. \& Fischer, J.A. (2008). A Drosophila model for Angelman syndrome. Proc Natl Acad Sci, 105:12399-12404.

Østergaard, J.R. \& Balslev, T. (2001). Efficacy of different antiepileptic drugs in children with Angelman syndrome associated with 15q11-13 deletion: the Danish experience. Dev Med Child Neurol, 43:718-9. 


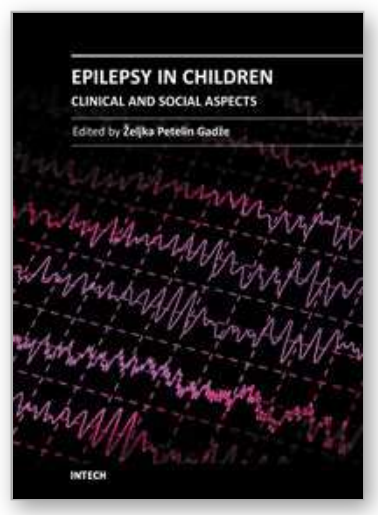

\author{
Epilepsy in Children - Clinical and Social Aspects \\ Edited by Dr. Zeljka Petelin Gadze
}

ISBN 978-953-307-681-2

Hard cover, 234 pages

Publisher InTech

Published online 15, September, 2011

Published in print edition September, 2011

Epilepsy is a neurological condition that accompanies mankind probably since its inception. About 400 years before Christ, the disease was already known by Hippocrates, who wrote the book â€œOn The Sacred Diseaseâ€. Classically, epilepsy has been defined as a chronic condition characterized by an enduring propensity to generate seizures, which are paroxysmal occurring episodes of abnormal excessive or synchronous neuronal activity in the brain. Out of all brain disorders, epilepsy is the one that offers a unique opportunity to understand normal brain functions as derived from excessive dysfunction of neuronal circuits, because the symptoms of epileptic seizures are not the result of usual loss of function that accompanies many disease that affect the brain. I am therefore extremely honoured to present this book. The 15 very interesting chapters of the book cover various fields in epileptology â $€$ " they encompass the etiology and pathogenesis of the disease, clinical presentation with special attention to the epileptic syndromes of childhood, principles of medical management, surgical approaches, as well as social aspects of the disease.

\title{
How to reference
}

In order to correctly reference this scholarly work, feel free to copy and paste the following:

Karine Pelc, Guy Cheron and Bernard Dan (2011). The Lessons from Angelman Syndrome for Research and Management, Epilepsy in Children - Clinical and Social Aspects, Dr. Zeljka Petelin Gadze (Ed.), ISBN: 978953-307-681-2, InTech, Available from: http://www.intechopen.com/books/epilepsy-in-children-clinical-andsocial-aspects/the-lessons-from-angelman-syndrome-for-research-and-management

\section{INTECH}

open science | open minds

\section{InTech Europe}

University Campus STeP Ri

Slavka Krautzeka 83/A

51000 Rijeka, Croatia

Phone: +385 (51) 770447

Fax: +385 (51) 686166

www.intechopen.com

\section{InTech China}

Unit 405, Office Block, Hotel Equatorial Shanghai

No.65, Yan An Road (West), Shanghai, 200040, China

中国上海市延安西路65号上海国际贵都大饭店办公楼405单元

Phone: +86-21-62489820

Fax: $+86-21-62489821$ 
(C) 2011 The Author(s). Licensee IntechOpen. This chapter is distributed under the terms of the Creative Commons Attribution-NonCommercialShareAlike-3.0 License, which permits use, distribution and reproduction for non-commercial purposes, provided the original is properly cited and derivative works building on this content are distributed under the same license. 